\title{
O social-trabalhismo do deputado federal Guerreiro Ramos
}

\author{
The Social-Labour of Congressman Guerreiro Ramos
}

Américo Freire ${ }^{1}$

Fundação Getulio Vargas / Escola de Ciências Sociais (CPDOC), Rio de Janeiro-RJ, Brasil

\begin{abstract}
Resumo
Este artigo analisa a atuação e as proposições políticas do deputado federal Alberto Guerreiro Ramos (1915-1982) na conjuntura crítica que antecede o golpe civil-militar de 1964. A pesquisa está referenciada nos discursos proferidos pelo parlamentar na Câmara dos Deputados entre agosto de 1963 e abril de 1964 e propõe o estudo dos principais temas contidos nos seus pronunciamentos. Três aspectos são sublinhados no texto: seu projeto de reformulação do Partido Trabalhista Brasileiro, do qual era figura destacada; suas concepções em defesa do socialismo democrático; e suas críticas frontais às direitas e ao Partido Comunista Brasileiro (PCB). Nas considerações finais, são apresentadas breves pistas de análise sobre o legado político-intelectual de Alberto Guerreiro Ramos.
\end{abstract}

Palavras-chave: Guerreiro Ramos. Atuação parlamentar. Trabalhismo. Socialismo.

\begin{abstract}
This article analyzes the role and political propositions of Congressman Alberto Guerreiro Ramos (1915-1982) in the critical juncture preceding the civil-military coup of 1964. The research is referenced in speeches made by the representative between August 1963 and April 1964 and proposes the study of the main topics contained in these pronouncements. Three aspects are highlighted in the text: its restructuring project of the Brazilian Labor Party, of which he was an important member; his views in defense of democratic socialism; and his external criticism of the right wings and the Brazilian Communist Party (PCB). In the final considerations, a brief analysis about the political and intellectual legacy of Alberto Guerreiro Ramos is presented.
\end{abstract}

Keywords: Guerreiro Ramos. Congressman. Labour. Socialism.

\section{Introdução}

\section{O social-trabalhismo do deputado federal Guerreiro Ramos}

Ao receber o convite do professor Fernando Guilherme Tenório para participar deste evento, propus uma breve incursão em um momento curto e intenso da longa carreira de Alberto Guerreiro Ramos como homem público: sua trajetória como deputado federal pelo Partido Trabalhista Brasileiro (PTB), pelo então Estado da

Artigo recebido em 26 de janeiro de 2015 e aceito para publicação em 24 de abril de 2015.

DOI: http://dx.doi.org/10.1590/1679-395149071

1 Doutor em História Social pela UFRJ; Professor Associado do Centro de Pesquisa e Documentação de História Contemporânea do Brasil da Fundação Getulio Vargas e Pesquisador de Produtividade em Pesquisa (PQ) do Conselho Nacional de Desenvolvimento Científico e Tecnológico (CNPq). Endereço: FGV/CPDOC. Praia de Botafogo, 190 - 14º andar - CEP 22250-900, Rio de Janeiro-RJ, Brasil. E-mail: americo.freire@fgv.br 
Guanabara. Diante do seu aceite, pus-me a trabalhar no sentido de viabilizar aquela ideia que, devo dizer, foi facilitada por três razões.

A primeira delas, e por certo a mais importante, é que já existem alguns trabalhos de qualidade que mapearam o tema. Registro, aqui, dois deles: o de Wilson Pizza Junior (1997), ex-aluno e colaborador de Guerreiro; e um capítulo da tese de doutorado de Ariston Azevedo Mendes (2006). Ambos serviram de inspiração e referência para a elaboração deste texto.

Outra razão que facilita o trabalho do pesquisador nos dias de hoje é a possibilidade de acesso às informações via internet, no caso pelo site da Câmara dos Deputados, dos discursos proferidos por Guerreiro Ramos em sua rápida passagem como parlamentar. Inegavelmente, temos ali um rico manancial de fontes que merece ser consultado por futuros pesquisadores que almejem compreender melhor como Guerreiro Ramos pensava, debatia e agia ${ }^{2}$.

Meu trabalho tornou-se menos árduo, também, devido ao fato de Guerreiro ter militado e ter sido eleito pela legenda PTB - uma agremiação que foi intensamente estudada por uma geração de pesquisadores do Centro de Pesquisa e Documentação de História Contemporânea do Brasil da Fundação Getulio Vargas (CPDOC/FGV), capitaneados pelas professoras Angela Maria de Castro Gomes e Maria Celina D'Araújo ${ }^{3}$. Nos últimos tempos, também tenho estudado alguns aspectos constituidores dessa "família política", cuja importância é inegável na história contemporânea brasileira até os dias de hoje - ontem menos do que hoje .

Este texto está dividido em duas partes. Na primeira, de cunho mais informativo, apresento um inventário de questões levantadas pelo então deputado federal Guerreiro Ramos. Dois são os níveis de análise aqui. O primeiro é de cunho temático, ou seja, volta-se a verificar quais eram os principais assuntos que estavam em sua cabeça naquela quadra de intensa radicalização política no Brasil, ou seja, entre o fim de 1963 e os primeiros meses de 1964 até o desfecho de março/abril de 1964. Outro nível de análise diz respeito ao seu posicionamento quanto à conjuntura política em tela. A pergunta, aqui, é simples e direta: Guerreiro Ramos atuou como "bombeiro" ou instigou o processo revolucionário pela esquerda?

A segunda parte trata de seu projeto para o PTB. Como ele via o partido? Qual era o caminho a ser traçado pela agremiação? Como o PTB deveria lidar com as críticas à esquerda e à direita?

Termino com breves reflexões sobre seu legado político-intelectual. Por fim, antes de dar a partida, advirto os leitores acerca do caráter exploratório deste paper que, antes de tudo, deve ser visto como um roteiro para futuras pesquisas sobre o projeto político-partidário de Guerreiro Ramos e outros intelectuais do mesmo cariz que, naquele contexto de transformações sócio-politico-culturais, buscaram compor um perfil ideológico mais claro ao PTB varguista e janguista.

\section{Inventário temático}

Nos anos 1950, foram estreitas as relações de Guerreiro Ramos com o projeto nacional-desenvolvimentista de inspiração varguista. Sua trajetória profissional dá provas disso, seja como assessor do presidente Getúlio Vargas (1882 - 1954) durante seu segundo governo (1951-1954), seja como diretor do departamento de

\footnotetext{
${ }^{2}$ Fui auxiliado na pesquisa documental e bibliográfica por Fabrício Souza Gomes, meu aluno de doutorado no Centro de Pesquisa e Documentação de História Contemporânea do Brasil da Fundação Getulio Vargas (CPDOC/FGV), a quem registro meu agradecimento.

${ }^{3}$ É vasta a produção do CPDOC sobre o trabalhismo e sobre o PTB. Sobre o tema, conferir em especial Gomes (2005) e D’Araújo (1996).

${ }^{4}$ Tenho estudado uma das vertentes do trabalhismo associada à trajetória de Leonel Brizola. Sobre o tema, ver Freire (2012). Ver, também, Freire e Azevedo (2011).
} 
sociologia do Instituto Superior de Estudos Brasileiros (ISEB). Nem os famosos embates e rachas que terminaram por marcar as relações entre os próceres isebianos, cujo resultado foi sua saída da instituição em 1958, o fizeram afastar-se do ideário trabalhista ${ }^{5}$. Pelo contrário. Foi exatamente nessa mesma quadra que, em seguida à sua autoexclusão do ISEB, passou a integrar o Diretório Nacional do PTB. Na ocasião, Guerreiro Ramos via-se motivado em deixar de ser um "sociólogo de gabinete" para, em tempo integral, transformar-se em "sociólogo em mangas de camisa". Como consequência disso, em 1962, saiu candidato a deputado federal pela legenda do PTB do Estado da Guanabara, então governado por Carlos Lacerda (1914 1977) - inimigo de morte do PTB.

$\mathrm{Na}$ campanha, Guerreiro defendeu um conjunto de proposições coerente com as "reformas de base" e com uma política externa independente. Propugnou, entre outros pontos, uma maior participação dos trabalhadores na programação e nos resultados do desenvolvimento econômico. Defendeu, ainda, a organização de um mercado nacional de capitais, a nacionalização imediata das concessionárias estrangeiras de serviço público (à moda de Brizola no Rio Grande do Sul); a regulamentação do direito de greve, além de comprometer-se com a defesa dos interesses do Estado da Guanabara no plano federal (AZEVEDO, 2006).

O candidato novato enfrentou inúmeros problemas na campanha, registrados em detalhes em "Mitos e verdade da Revolução Brasileira (GUERREIRO RAMOS, 1963). Nesse livro, relata as artimanhas empreendidas contra ele por líderes do Partido Comunista Brasileiro (PCB), que o acusavam de barrar a presença de candidatos comunistas na legenda do PTB. Guerreiro Ramos nega a acusação, mas não deixa de desferir graves críticas ao PCB. Ao mesmo tempo, nunca deixou de defender a legalização do partido. Veremos adiante esse ponto em detalhe.

Guerreiro Ramos teve um número de votos modesto, mas suficiente para ser eleito suplente da legenda, na esteira da espetacular votação obtida por Leonel Brizola (1922 - 2004) no pleito de 1962. Em agosto de 1963, assumiu a cadeira da Câmara dos Deputados devido ao afastamento de Brizola do órgão. Na ocasião, este estava empenhado em algo para além de seu trabalho como parlamentar: percorria o país a mobilizar as massas para fazer frente à radicalização política.

Guerreiro Ramos permaneceu como deputado entre 26 de agosto de 1963 e 17 de abril de 1964. Segundo Pizza Junior (1997) e Azevedo (2006), subiu 71 vezes à tribuna, apresentado somente 5 projetos de lei, a saber: sobre licenciamento de patentes; sobre exercício da profissão de técnico de administração; sobre questões relativas às carreiras de funcionários do Poder Executivo; um projeto de emenda constitucional que torna obrigatória a apresentação de um plano quinquenal pelo Presidente da República; e, por fim, um projeto a respeito de questões relativas aos juros de instituições bancárias oficiais.

Seus discursos versaram sobre temas muito variados, fossem questões relativas a problemas internacionais como o papel da Organização das Nações Unidas (ONU) ou temas relativos ao mundo socialista -, fossem questões domésticas - como greves, funcionalismo, planejamento econômico, mercado interno de capitais etc. Ainda que Guerreiro Ramos, em seus discursos e proposições, se valesse de sua condição de professor e sociólogo reconhecido e admirado por seus pares para firmar suas posições, na Câmara dos Deputados fez o que costumeiramente faz um parlamentar, isto é, em seu dia a dia, pela natureza da função, via-se envolto a lidar com todo tipo de questão, da mais comezinha à mais importante.

Mesmo assim, em meio a um emaranhado de assuntos, Guerreiro Ramos teve condições de dedicar-se a alguns temas de sua preferência, como nos mostra Azevedo (2006). Foram eles: a defesa da reforma agrária; o papel e o significado da ONU; e, por fim, o tema de sua predileção, o embate político-ideológico com a direita e com esquerda. Por mais que, na ocasião, a questão da reforma agrária fosse o que despertasse debates mais acerbos entre as diferentes forças políticas, fiquemos, por ora, para fins de análise, apenas com o último tema.

\footnotetext{
${ }^{5}$ Sobre a trajetória do ISEB, ver, entre outros, o trabalho seminal de Abreu (1975). Ver, também, Toledo (2005) e Pereira (2002).
} 
Quanto às direitas, Guerreiro Ramos aprazia-se em subir à tribuna para bater impiedosamente em Carlos Lacerda - adversário histórico dos trabalhistas. Chegou mesmo a cunhar a categoria "lacerdismo" para caracterizar aquele tipo de atitude política de cunho marcadamente passional, sanguínea, que ignora ou finge ignorar o condicionamento histórico-social da conduta humana (GUERREIRO RAMOS, 1963).

Para Guerreiro Ramos, Lacerda era o protótipo da direita entreguista, antinacional, que, em determinado momento, chegara até a defender a implantação de uma ditadura em moldes salazaristas no país (Discurso na Câmara dos Deputados, sessão de 24/01/1964). Em janeiro de 1964, ao comentar em discurso na tribuna da Câmara dos Deputados a respeito escolha da União Democrática Nacional (UDN) do nome de Lacerda à Presidência da República, Guerreiro Ramos assim se referiu:

Não posso, infelizmente, me alongar na análise complexa do governador da Guanabara. [...] Sua Ex. ${ }^{a}$ em toda sua carreira política, se tem caracterizado como homem formado à imagem e semelhança do Pentágono. É tecnicamente um homem do Pentágono. [...]

Não posso acreditar que homens respeitáveis como o Sr. Pedro Aleixo, como o Sr. Bilac Pinto [...] tenham a consciência feliz neste momento, carregando um candidato à presidência como o Sr. Carlos Lacerda (Discurso na Câmara dos Deputados, sessão de 24/01/1964).

Guerreiro Ramos dizia-se um homem de esquerda que se dispunha a fazer a "crítica da esquerda pela esquerda". A par de fazer profissão de fé no socialismo - que via como "lei fundamental do mundo contemporâneo" - em nenhum momento deixava de colocar em questão a experiência comunista soviética. Para efeito de síntese, vejamos algumas de suas formulações sobre o tema que se encontram expressas em seus discursos e em Guerreiro Ramos (1963):

1. Para Guerreiro Ramos, o mundo do pós-guerra vivia uma situação revolucionária sui generis, inédita até então - impulsionada, entre outros fatores, pela universalização da civilização. Com isso, o socialismo, antes restrito a determinados países, tornou-se um processo mundial. O socialismo, pela ação consciente dos homens, sublinha o autor: "é o modelo de toda revolução popular da presente época, independentemente da qualidade do modo de produção" (GUERREIRO RAMOS, 1963, p. 44). Em razão disso, conclui Guerreiro Ramos (1963, p. 44), resulta em "anacrônico o clássico modelo marxista de revolução, segundo o qual cada sociedade teria de percorrer, um após o outro, os diferentes modos de produção até chegar ao socialismo. O modelo tem validade restrita". E continua: "Não há nada mais pernicioso ao trabalho revolucionário do que os escritos de Marx, Engels, Lenin, Stalin, Mao-Tse-Tung, quando lhe emprestam atributos bíblicos ou evangélicos" (GUERREIRO RAMOS, 1963, p. 46).

2. Para Guerreiro Ramos, a atitude revolucionária comportava: indignação moral contra a injustiça; consciência da razão histórica da época, ou seja, cabe ao revolucionário deter "fé sociológica"; crer na ação do indivíduo para a ação revolucionária; não se submeter a modelos finais de revolução, antes, pelo contrário, confiar na possibilidade de inovar no terreno da estratégia e da tática, a fim de responder adequadamente ao ineditismo de vicissitudes históricas concretas; manter uma atitude realista, não sacrificando um avanço possível por uma exigência supostamente ortodoxa que exorbite das condições viáveis em determinado momento (GUERREIRO RAMOS, 1963).

3. Guerreiro Ramos era crítico contumaz do marxismo-leninismo soviético. Para ele, a experiência soviética pode ser vista, quando muito, como "socialismo de Estado" ou mesmo como um "capitalismo de Estado". Sobre isso, registra o seguinte trecho de Isaac Deutcher - figura de proa no combate ao stalinismo: "Lenin recorreu às práticas de Pedro, o Grande, a fim de preparar a Rússia para o socialismo no plano industrial, no técnico e no pedagógico. E depois de Lenin, Stalin, observando o princípio autocrático, consolidou o bolchevismo como uma liga de marxismo ocidental e barbárie russa". (GUERREIRO RAMOS, 1963, p. 70). 
4. Para ele, "o marxismo-leninismo não é um pensamento, não é uma teoria; o marxismo leninismo é uma organização de combate e de choque que manipula uma técnica de agitação e propaganda, com o objetivo de assaltar o poder; é uma organização destituída ou esvaziada de conteúdo ético [...]".(Referência: Discurso na Câmara dos Deputados, sessão de 10/12/1963.

Fiquemos por aqui. Há muito mais em seus escritos e discursos sobre o tema. Vale o registro de que suas críticas ao bolchevismo não negavam a importância do marxismo como modo de interpretação do real, como faziam e fazem os conservadores e liberais. Longe disso. Sua abordagem sobre o tema não era em nada parecida com o anticomunismo histérico que andava à solta e era conclamado por amplos setores da Igreja Católica, da UDN e de outras forças de cunho conservador ${ }^{6}$.

Daí, portanto, é fácil de entender as razões pelas quais Guerreiro Ramos se posicionava favoravelmente à legalização do PCB - uma tese que dividia opiniões nas casas legislativas e na sociedade em geral. Sobre esse tema, valia-se, também, de argumentos pragmáticos e que diziam respeito a questões específicas nas complexas relações existentes entre o PCB e o PTB. Explico.

Como já apontei aqui, Guerreiro Ramos ressentia-se da campanha que o PCB fez contra ele durante a campanha eleitoral, acusando-o de anticomunista e de ter barrado a participação de comunistas na chapa petebista. Exatamente por isso, defendia que, com a legalização, o PCB poderia deixar de valer-se da antiga prática do entrismo em legendas próximas ideologicamente, seja o PTB, o PSB e até, por vezes, o Partido Social Progressista (PSP), de Ademar Barros (1901 - 1969). Vejamos um breve trecho de Guerreiro Ramos a esse respeito:

O político tem posição interessada. Estou aqui defendendo interesse meu, pessoal, e o meu interesse coincide com o do Brasil. Porque eu não tenho saída, não tenho futuro político neste País, [...] se continuar essa confusão do Partido Comunista infiltrado em todas as organizações de esquerda no Brasil. [...] Não estou defendendo uma posição abstrata: estou defendendo uma posição pragmática, de importância para a carreira de homens como eu, que são socialistas, mas não querem receber figurinos importados, diretrizes importadas e, sim, querem conduzir-se por critérios induzidos das conveniências do País. É um problema pragmático, não é um problema estético este que eu estou levantando. De modo que, por essas razões, sou favorável à legalização do Partido Comunista, porque isso virá clarificar a área da esquerda no Brasil (Discurso na Câmara dos Deputados, sessão de 18/02/1964).

Por fim tratemos do posicionamento desse socialista-trabalhista na conjuntura de radicalização pela qual passou o país nos dias/meses que antecederam ao golpe civil-militar de 1964.

Em seus pronunciamentos, Guerreiro Ramos dividia as forças de esquerda em duas. Por um lado, uma esquerda que buscava monopolizar o movimento libertador brasileiro; era catastrofista, infanto-juvenil e bovarista - isto é, tende a superdimensionar suas forças, a magnificar seu prestígio. Por outro lado, emerge uma esquerda consequente, independente e madura, da qual faz parte. Trata-se, em suas palavras, "de uma esquerda legalista, que defende as instituições legais do país e que lutará para o encaminhamento democrático e legal dos problemas políticos, econômicos e culturais do Brasil”"

E conclui:

[...] é uma esquerda gradualista por princípio no sentido de que fará tudo para evitar o dramatismo e a violência na resolução dos problemas nacionais, fará tudo para evitar uma revolução sangrenta sempre que for possível [...] porque está convicta que no balanço dos fatores do país há possibilidade tranquila para soluções gradualistas e, portanto, condena

\footnotetext{
${ }^{6}$ Para o estudo do anticomunismo, ver trabalho lapidar de Motta (2002).
} 
aqueles que alardeiam o dramatismo e assustam as populações do Brasil, levando essas populações, que são muito mais inteligentes do que pensa, para a direita e para o fascismo (Discurso na Câmara dos Deputados, sessão de 31/01/1964).

Ao proferir essas palavras, em fins de janeiro de 1964, ou seja, em meio a uma conjuntura de agravamento da crise política, Guerreiro Ramos deixa explícito seu apoio a Jango João Goulart a seu governo. Não vê caminho senão a realização das mudanças estruturais que o país precisava e necessitava pela via da democracia e pelo respeito às instituições. Combatia, portanto, o catastrofismo golpista alimentado pela esquerda "infantil" e pela direita fascista. Via, por fim, no PTB, o instrumento político essencial capaz de reunir a "esquerda madura e consequente" com vistas a conduzir o movimento de libertação nacional.

\section{PTB e trabalhismo}

Como já indicamos aqui, Guerreiro Ramos ingressou no PTB no final dos anos 1950. Na ocasião, o partido tomava corpo e colocava-se como real alternativa de poder. Tanto que, no pleito federal de 1962, tornou-se a segunda bancada na Câmara dos Deputados. Sob a liderança do então presidente João Goulart, o partido compunha diferentes tendências, seja as mais moderadas e voltadas à defesa do governo e à garantia da ordem, seja as mais radicais e extremistas, capitaneadas pelo ex-governador gaúcho Leonel Brizola ${ }^{7}$.

O PTB mantinha uma relação de disputa e aproximação com o PCB, então na ilegalidade. Não poucas vezes, atuavam em conjunto no movimento sindical e popular. Também, por vezes, o partido abrigava comunistas em suas fileiras - como forma de agregar maior densidade eleitoral em importantes centros urbanos, como o Rio de Janeiro e São Paulo .

Por outro lado, o PTB pagava um preço nesse jogo de alianças com o PCB, já que era confundido com a agremiação e com as práticas comunistas. Daí a necessidade sentida pela direção do partido em se demarcar mais claramente dos comunistas junto à opinião pública. Nesse contexto, ganharam importância no PTB alguns intelectuais que deveriam cumprir essa função, entre os quais os mais importantes foram San Tiago Dantas (1911-1964) - figura de amplo prestígio nos meios intelectuais e políticos - e o próprio Guerreiro Ramos 9 .

Em seus escritos e pronunciamentos, Guerreiro Ramos deixou explícito seu interesse em participar dessa demarcação, com vistas a tornar claro o que via como linha programática do PTB. Fiquemos aqui, por hora, com dois documentos onde são registradas suas posições e suas propostas para o partido.

O primeiro é uma declaração redigida por ele a pedido da Executiva do Partido da Guanabara, onde são explicitadas as relações do PTB com o marxismo-leninismo. Nela são assinalados os seguintes pontos: 1) o PTB tem como objetivo emancipação do povo brasileiro, mediante a instauração no país de um poder a serviço exclusivo dos interesses da coletividade brasileira; 2) o PTB só defende soluções brasileiras para os problemas brasileiros [...] e não reconhece a validade objetiva do marxismo-leninismo, doutrina que, historicamente, sob disfarce da ciência, tem sido instrumento de direção monopolística, em escala mundial, de movimentos políticos e agitações de massa (grifo nosso); 3) o PTB proclama sua vocação socialista, mas não admite nenhum figuro pré-fabricado de socialismo, o qual só poderá vingar no Brasil, na medida em que for gerado pelas condições particulares da história do nosso povo (grifo nosso); 4) o PTB conclama todas as forças populares à união, a fim de, no próximo pleito de 7 de outubro, eleger aos postos parlamentares candidatos autenticamente nacionalistas (grifo nosso); 5) o PTB está aberto a alianças que,

\footnotetext{
${ }^{7}$ Para o estudo da ação radical de Leonel Brizola na conjuntura, ver Ferreira (2007).

${ }^{8}$ Para as complexas relações entre comunistas e petebistas, ver Santana (2007).

${ }^{9}$ Sobre o projeto e a trajetória de San Tiago Dantas no PTB, ver Onofre (2012).
} 
sem prejuízo de seus princípios, contribuem para a constituição de sólida frente popular contra os inimigos das causas dos trabalhadores (grifo nosso).

Como se pode verificar, os termos são diretos e muito claros. O PCB é visto como monopolista, antinacional e estranho aos reais interesses do povo brasileiro. Em razão disso, o marxismo-leninismo é rechaçado enfaticamente como doutrina incapaz de responder aos reclamos da revolução brasileira.

Em janeiro de 1964, durante os debates acerca da legalização do PCB, Guerreiro Ramos faz importante pronunciamento acerca do que entendia como o papel e o significado do PTB para o futuro do país e, em especial, para o futuro econômico do país. Para ele, o lema que deveria pautar o partido era: trabalhismo e eficiência. Essa bandeira desdobra-se em dez pontos citados em discurso na Câmara dos Deputados (sessão de 31/01/1964), assim resumidos: 1) governo barato e administração racionalizada e moralizada; 2) consolidação do mercado oficial de capitais e estruturação das instituições do capital financeiro; 3 ) encorajamento do setor público da economia e criação de base para o florescimento do empresariado privado; 4) modernização da agricultura e redistribuição gradativa da propriedade fundiária; 5) combate aos super e aos subsalários; 6) desenvolvimento econômico e social sem interferência estrangeira; 7) constituição de autêntica força de libertação nacional; 8) democratização do poder mediante atualização da lei eleitoral dos partidos políticos; 9) integração econômica do país e atualização do pacto federativo; 10) encorajamento à política externa independente.

Exatos três meses depois desse discurso adveio o golpe que promoveu a cassação de Guerreiro Ramos e de inúmeros quadros e parlamentares do PTB. Configurava-se a vitória do "lacerdismo" e do "golpismo", tão combatidos por ele. Ele fez seu último pronunciamento na Câmara dos Deputados em 15 de abril de 1964.

\section{Considerações finais}

Concluo tratando, em brevíssimos termos, de um último ponto: os contornos do projeto social-trabalhista do deputado Guerreiro Ramos e o legado desse projeto para as esquerdas brasileiras.

Em sua atuação parlamentar, como acima nos referimos, Guerreiro Ramos bateu-se por levar adiante uma definição mais clara do programa doutrinário do PTB, com vistas a ajustar a atuação do partido aos reclamos daquela conjuntura crítica. Para ele, a legenda deveria integrar três eixos: o nacionalismo terceiro-mundista de libertação nacional - arma de que se vale para combater "entreguistas" e "internacionalistas marxistas leninistas"; o socialismo construído em termos genuinamente brasileiros - o que, aqui, denomino "socialtrabalhismo"; e, por fim, um conjunto de proposições com vistas a racionalizar e modernizar as estruturas econômicas do país e administrativas do governo.

Cassado em 1964, Guerreiro Ramos foi abrigado na Fundação Getulio Vargas (FGV) por um tempo, para depois deixar o país rumo aos EUA. Seu legado político tem sido objeto de discussão.

Para minhas pesquisas, a pergunta-chave é como perfilhar seu pensamento político na história das esquerdas brasileiras - seja antes, seja depois do marco fatal de 1964 ?

Trata-se de tarefa complexa e que demanda mais pesquisas e mais tempo de exposição. Fico por aqui, com o registro de três breves possibilidades de pesquisa sobre a herança de Guerreiro Ramos:

1. Creio ser fértil o caminho sugerido pelo sociólogo Luiz Eduardo Motta (2010), que estabelece uma conexão entre o pensamento nacionalista de viés terceiro-mundista de Guerreiro Ramos com a vertente marxista da Teoria da Dependência, capitaneada por Teotônio dos Santos (1936-....) e Ruy Mauro Marini (1932-1997).

2. Um dado não desprezível de suas formulações diz respeito ao seu apreço pela revolução, pela mudança, mas pela via democrática. Guerreiro Ramos deixava clara sua desconfiança com os esquerdismos de cariz golpista. 
3. Ainda faltam estudos sobre suas proposições modernizantes no plano econômico-financeiro, voltadas a um funcionamento mais racional da economia capitalista e da máquina pública. Como integrar esses aspectos no âmbito de um projeto socialista? Como relacionar modernização gerencial/capitalista e transformações sociais? Ficam essas perguntas no ar.

\section{Referências}

ABREU, A. A. Nacionalism et action politique au Brésil: une etude sur l'ISEB. Paris: Université René Descartes, 1975.

AZEVEDO MENDES, A. A sociologia antropocêntrica de Alberto Guerreiro Ramos. Tese (Doutorado em Sociologia Política) - Universidade Federal de Santa Catarina, Florianópolis, 2006. 355 p.

D’ARAÚJO, M. C. Sindicato, carisma e poder: o PTB de 1945 a 1964. Rio de Janeiro: Ed. FGV, 1996.

FERREIRA, J. Leonel Brizola, os nacionalistas-revolucionários e a Frente de Mobilização Popular. In: FERREIRA, J.; REIS, D. A. Nacionalismo e reformismo radical (1945-1964). Rio de Janeiro: Civilização Brasileira, 2007. v. 2. 543584 p. (Coleção As Esquerdas no Brasil).

FREIRE, A. O Rio de Janeiro de Leonel Brizola. In: FREIRE, A. Sinais trocados: o Rio de Janeiro e a República brasileira. Rio de Janeiro: Sete Letras, 2012. 251-276 p.

FREIRE, A.; AZEVEDO, F. Intervenção política, imprensa e democracia: os tijolaços de Leonel Brizola. Anos 90: Revista do Programa de Pós-Graduação em História da UFRGS, v. 18, n. 33, p. 15-40, jul. 2011.

GOMES, A. C. A invenção do trabalhismo. 3. ed. Rio de Janeiro: Ed. FGV, 2005.

GUERREIRO RAMOS, A. Mito e verdade na Revolução Brasileira. Rio de Janeiro: Zahar, 1963.

MOTTA, L. E. A política do Guerreiro: nacionalismo, revolução e socialismo no debate brasileiro nos anos 1960 . Organizações \& Sociedade, v. 17, n. 52, p. 85-101, 2010.

MOTTA, R. P. S. Em guarda contra o perigo vermelho: o anticomunismo no Brasil. São Paulo: Perspectiva, 2002.

ONOFRE, G. Em busca da esquerda esquecida: San Tiago Dantas e a Frente Progressista. Dissertação(Mestrado em História, Política e Bens Culturais X) - Centro de Pesquisa e Documentação de História Contemporânea do Brasil, Fundação Getulio Vargas, Rio de Janeiro, 2012.

PEREIRA, A. E. O ISEB na perspectiva do seu tempo. Tese (Doutorado em Ciência Política) - Universidade de São Paulo, São Paulo, 2002.

PIZZA JUNIOR, W. Trajetória parlamentar de Alberto Guerreiro Ramos. Rev. Adm. Pública, v. 31, n. 5, p. 24-28, 1997.

SANTANA, M. A. Bravos companheiros: a aliança comunista-trabalhista no sindicalismo brasileiro. In: FERREIRA, J.; REIS, D. A. Nacionalismo e reformismo radical (1945-1964). Rio de Janeiro: Civilização Brasileira, 2007. v. 2. 237277 p. (Coleção As Esquerdas no Brasil).

TOLEDO, C. N. (Org.). Intelectuais e política no Brasil. A experiência do ISEB. Rio de Janeiro: Revan, 2005. 